group also compared the properties of untreated composite fibers containing MWNTs to those containing single-walled nanotubes (SWNTs).

The scientists spun their continuous fibers by injecting a homogeneous dispersion of nanotubes into a co-flowing stream of aqueous PVA. They then investigated the mechanical properties under tensile load. Toughness is measured by the specific amount of energy that is required to break a fiber and the amount of strain tolerated before failure. Their untreated SWNT fibers reached a record strain-to-failure of $430 \%$ and an unprecedented toughness of $870 \mathrm{~J} / \mathrm{g}$. Untreated MWNT/PVA fibers performed nearly as well. These composite fibers are an order of magnitude tougher than polyaramide fibers such as Kevlar.

Unfortunately, classical nanotube/PVA composite fibers swell and lose strength in humid conditions, and they absorb relatively little energy at low strain, compared with polyaramides. Miaudet and co-workers drew inspiration from textile technologies and remedied both drawbacks by hot-drawing their nanotube/ PVA fibers. After drying the fibers, they pulled them to $850 \%$ within a hot air stream at $180^{\circ} \mathrm{C}$, which is above the PVA glass transition.

$X$-ray diffraction confirms that the hot-drawing process increases the crystallinity of the PVA and further aligns the PVA chains and the nanotubes. This microstructural change enhances the stress transfer between the polymer and the nanotubes. The hotdrawn fibers are radically stronger and absorb much more energy at lower strain. Furthermore, because crystalline PVA does not dissolve in water at room temperature, the treated fibers retain their mechanical properties in humid conditions and do not become bloated, even when submerged.

Even stronger fibers are a possibility. "The nanotubes are still not as well-aligned as the PVA chains are," said Miaudet, "but this problem may be solved if we use straighter or less entangled nanotubes. It is predicted that the Young's modulus will grow by an order of magnitude during the last degrees of alignment."

RICH LOUIE

\section{Single Screw-Sense Cylindrical Nanoshutter Driven by Thermal and Solvent-Polarity Changes}

Molecular motors are nanomachines that perform work by transforming low-input energy sources, such as thermal energy or solvent-polarity changes, into mechanical motion. Potential applications for nanomotors include data storage, optical devices, and liquid-crystalline displays. Recently, researchers from the Department of Chemistry at North Carolina State University (Raleigh, N.C.), and the Department of Chemistry at Vanderbilt University (Nashville, Tenn.) developed a new model for a nanomotor-a cylindrical shutter consisting of a thermal and solvocontrollable switching polyguanidine derivative - in which the switching phenomena does not involve inversion of the polymer backbone.

As reported in the November 11, 2005, issue of Angewandte Chemie International Edition (p. 7298; DOI: 10.1002/anie. 200501977), North Carolina State University researcher B.M. Novak, Vanderbilt University researcher P.L. Polavarapu, and co-researchers used helix-sense-selective polymerization to synthesize the species shown in Figure 1, which is chiral because the backbone possesses a single-handed screw sense and the anthracene and imine are stereoregular. While complete racemization requires high temperatures and long periods of time (nearly $80^{\circ} \mathrm{C}$ and $>100 \mathrm{~h}$ ), switching of electronic circular dichroism (ECD) and UV-vis spectra occurs within seconds at moderate temperatures. At $38.5^{\circ} \mathrm{C}$, the Cotton effect (i.e., the production of circular birefringence under electromagnetic radiation) at $382 \mathrm{~nm}$ in ECD spectra switches from positive to negative. Similarly, UV-vis spectra show a strong absorption at $382 \mathrm{~nm}$ at $25^{\circ} \mathrm{C}$, but a weaker absorption at $60^{\circ} \mathrm{C}$. Concomitant switching of the vibra-

\section{Precision Heating} to $1200^{\circ} \mathrm{C}$ in 24 seconds, for under $10 \mathrm{~K}$ ?

\section{NOW THAT'S HOT!}

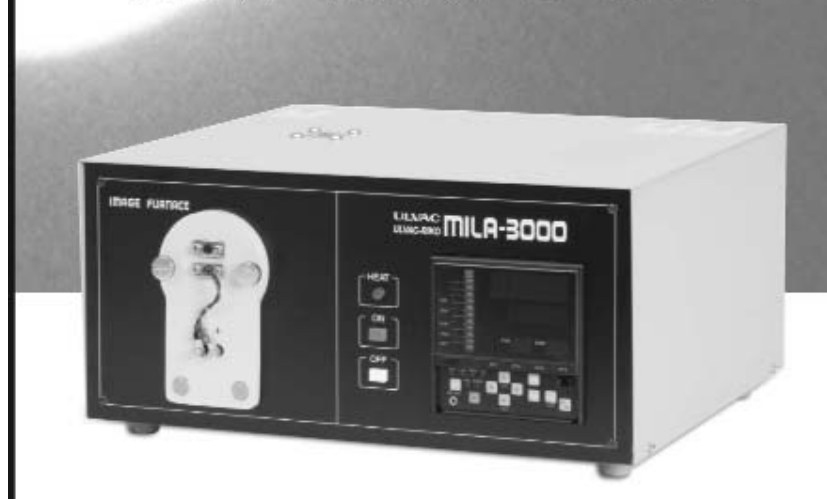

Anneal your small samples faster and with better control using the programmable MILA-3000 tabletop furnace. Ulvac's Mini-Lamp Annealing System can rapidly heat and cool samples with it's infrared gold image furnace, providing precision high temperature control, clean heating and versatile atmosphere selection.

\section{MILA-3000 Features:}

- High controlled heating rates of $50^{\circ} \mathrm{C} / \mathrm{s}$

- Sample size $20 \times 20 \times 20 \mathrm{~mm}$

- Air, vacuum and inert/reactive gas atmosphere

- Temperature uniformity of $+/-2^{\circ} \mathrm{C}$

- Low power consumption $(1 \mathrm{~kW})$

For all your annealing and thermal processes, turn on the heat with the MILA-3000!



For more information, see http://advertisers.mrs.org 


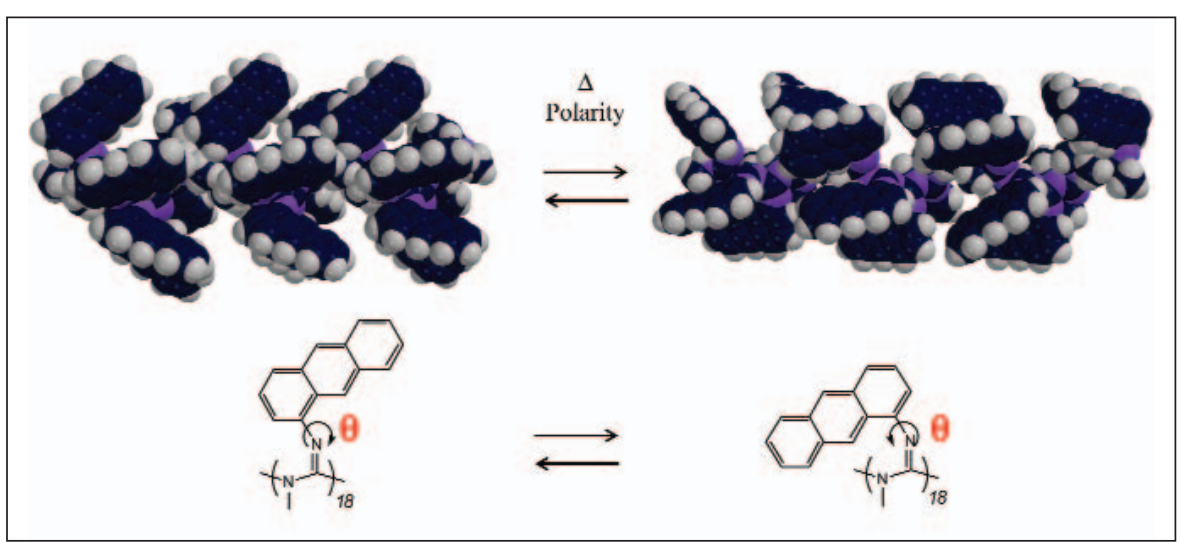

Figure 1. Theoretical models of the two states that result from the shutter-like motions of the anthracene unit.

tional circular dichroism (VCD), however, was not observed, which the researchers said indicated that the helical pitch remained constant during the other switching processes. The researchers reasoned that these observations can only be reconciled if the anthracene units wag syn- chronously around the N-C bonds in the anthracene moieties, which would change the orientation of the anthracenes relative to the nitrogens' lone-pair electrons (see Figure 1).

The researchers confirmed their hypothesis with theoretical molecular

models. Using a molecular model similar to the repeat unit in Figure 1 (suitably capped with hydrogens), semiempirical molecular orbital theory was used to show that shutter-like motions of the anthracenes do not affect the helical pitch or the imine configuration. The researchers obtained the same result for an 18-mer using molecular mechanics simulations. The researchers also performed density functional theory (DFT) calculations to obtain a theoretical VCD spectrum, which is in excellent agreement with the experimental spectrum, and to assign the chirality, which is difficult to do experimentally, as $P$. The researchers said that, "Further modification and applications are currently under investigation."

STEVEN TROHALAKI

\section{News of MRS Members/Materials Researchers}

ASM International has announced 2005 Awards and Fellows:

Alton D. Romig (Sandia National Laboratories), Acta Materialia, Inc., J. Herbert Hollomon Award;

Herbert L. Eiselstein (Inco Alloys International Inc.), ASM William Hunt Eisenman Award;

J. David Embury (McMaster University), ASM Edward DeMille Campbell Memorial Lecture

Stanley Abkowitz (Dynamet Technology Inc.), ASM Distinguished Life Membership;

John D. Hubbard (Bodycote International), ASM Distinguished Life Membership;

William J. Madia (Battelle), ASM \& TMS Distinguished Lecture in Materials \& Society;

Julia R. Weertman (Northwestern University), ASM Gold Medal;

Anthony G. Evans (University of Southern California, Santa Barbara), Alpha Sigma Mu Lecture;

Donald L. Runkle (Delphi Corp.), ASM Medal for the Advancement of Research;

Jack G. Simon (Westinghouse Savannah River Technology Center), ASM Allan Ray Putnam Service Award;

Kenneth Gall (University of Colorado), ASM Bradley Stoughton Award for Young Teachers;
Merton C. Flemings (Massachusetts Institute of Technology), ASM Albert Easton White Distinguished Teacher Award;

William Jones (Solar Atmospheres Inc.), HTS George H. Bodeen Award;

Gordon Hunter and William L. Griffin (Smith \& Nephew Orthopaedics), ASM Engineering Materials Achievement Award;

Yulin Lu (University of Tennessee), ASM Graduate Student Paper Contest;

Arden Bement Jr. (National Science Foundation), ASM Honorary Membership;

David M. Saylor (U.S. Food and Drug Administration); Anthony D. Rollett, Kee Young Jung, and Bassem S. ElDasher (Carnegie Mellon University); and Joseph Fridy (Alcoa Technical Center), ASM Henry Marion Howe Medal;

Kelly T. Conlon (Atomic Energy of Canada), Roger C. Reed (University of British Columbia), and David Dye (Imperial College), ASM Marcus A. Grossmann Young Author Award;

Alan J. Ardell (University of California, Los Angeles), ASM Albert Sauveur Achievement Award;

Peter King (Deakin University), 2005

HTS Bodycote Best Paper Award;

Aziz Asphahani (Carus Chemical Co.), ASM Materials Education
Foundation George A. Roberts Award; Kousuke Kimura, Satoshi Hata, Syo Matsumura, and, Takao Horiuchi (Kyushu University), ASM-IMS Jacquet Lucas Award;

Sergei A. Shipilov (University of Calgary), ASM Canada Council M. Brian Ives Lecturer;

Jean-Pierre Immarigeon (NRC Institute for Aerospace Research), ASM Canada Council G. MacDonald Young Award; and

Srinivasa Rao Boddapati (University of Washington), Mahesh Chaturvedi (University of Manitoba), Ramachandran Radhakrishnan (Materials Modification Inc.), and Srinivasan Shankar (Shankar Associates), ASM-IIM Visiting Lectureship.

ASM Fellows are Eugen Abramovici (Falcon Met Engineering and Laboratories Inc.), Riad I. Asfahani (U.S. Steel), GuoLiang Chen (University of Science \& Technology, Beijing), Pavel Chraska (Institute of Plasma Physics ASCR); J.R. Douglas (JRD Associates), John N. DuPont (Lehigh University), Omar S. Es-Said (Loyola Marymount University), Luther M. Gammon (Boeing Co.), Amit Goyal (Oak Ridge National Laboratory), Chester N. Grant (General Motors Powertrain), John F. Grubb (ATI Allegheny Ludlum), Darel Hodgson (Nitinol Technology Inc.), Susan J. 